\title{
Postharvest quality of hydroponic strawberry coated with chitosan-calcium gluconate
}

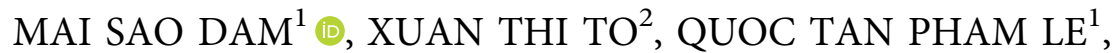 \\ LIEN LE PHUONG NGUYEN ${ }^{3 *}$ (), LÁSZLÓ FRIEDRICH ${ }^{3}$, GÉZA HITKA ${ }^{4}$ (อ), \\ TAMÁS ZSOM ${ }^{4}$, TIEN CAM THI NGUYEN ${ }^{1}$, CHUONG QUANG HUYNH $^{1}$, \\ MY DIEM THI TRAN ${ }^{1}$ and VUONG DUC NGUYEN ${ }^{1}$
}

${ }^{1}$ Institute of Biotechnology and Food Technology, Industrial University of Ho Chi Minh City, Viet Nam

${ }^{2}$ Office of Inspection, Food Safety Management Authority of Ho Chi Minh City, Viet Nam

${ }^{3}$ Department of Refrigeration and Livestock Product Technology, Szent István University, Budapest, Hungary

${ }^{4}$ Department of Postharvest Technology and Sensory Science, Szent István University, Budapest, Hungary

\section{CONFERENCE FULL PAPER}

Received: August 12, 2020 • Accepted: September 25, 2020

Published online: November 18, 2020

(C) 2020 The Author(s)

\begin{abstract}
The aim of this study was to evaluate the effect of edible coating on hydroponic strawberry during storage. Strawberries were coated with either $1 \%$ or $1.5 \%$ chitosan (CS) or with solution containing $1.5 \%$ chitosan and $0.5 \%$ calcium gluconate $(\mathrm{CaGlu})$. After treatment, samples were stored at $10{ }^{\circ} \mathrm{C}, \mathrm{RH} 90 \%$ for 10 days. The weight loss, soluble solid content, firmness, surface color, $\mathrm{pH}$, and percentage of decay were evaluated each day during the experiment. It was observed that coating extended the postharvest life of hydroponic strawberry compared to control. Fungal growth occurred on control group at the 5th day and fruit treated with $1 \%$ $\mathrm{CS}$ at the 8th day of the storage period, whereas no visible sign was detected for other treatments. Soluble solid content and $\mathrm{pH}$ showed only minor change for all samples. Weight loss of coated fruit was below $6 \%$ after 10 days of storage, whereas the weight loss of control samples was around $10 \%$ at the end of measurement. Moreover, coating could maintain the firmness of strawberry compared to the control. The combination of chitosan and calcium gluconate showed the potential for prolonging the storage period of hydroponic strawberry till 10 days without decay, whereas the control sample had more than $60 \%$ of rotted fruit.
\end{abstract}

"Corresponding author. E-mail: Nguyen.Le.Phuong.Lien@szie.hu 


\section{KEYWORDS}

chitosan, coating, hydroponic, strawberry, storage

\section{INTRODUCTION}

Nowadays, fruit market is in high demand, thus maintaining quality of fruit including nutrition, microbial safety, and specific characteristics during storage are necessary. In order to meet the market requirements, many technologies have been applied to prolong the postharvest life of fruit including chemical treatment (Nguyen et al., 2020a, Baranyai et al., 2020), edible coating (Hazarika et al., 2019), radiation treatment (Jesus Filho et al., 2018), modified atmosphere packaging (Rux et al., 2016), ethylene absorber (Nguyen et al., 2018), moisture absorber (Nguyen et al., 2020b).

Among these technologies, edible coating is one of the promising techniques in maintaining fresh quality of fruit and vegetable (Bautista-Baños et al., 2006). Application of chitosan as an edible coating is widely used in prolonging the shelf life of fruits and vegetables due to its nontoxic, biodegradable, and biocompatible properties (Duan et al., 2019). Chitosan-based coating has been applied successfully to preserve fresh attributes for strawberry (HernándezMuñoz et al., 2008), fig (Adiletta et al., 2019), citrus, apples, tomatoes, and cucumbers (Duan et al., 2019). Hernández-Muñoz et al. (2008) found that the combination of chitosan and calcium gluconate was able to improve the safety and quality of strawberry compared to chitosan alone.

Strawberry is one of the most favorite fruit due to its attractive color and taste. In addition, berry contains many valuable bioactive compounds (Dalmadi et al., 2007). However, this produce easily deteriorates after harvest with symptoms including desiccation, bruising, and rots (Hernández-Muñoz et al., 2008). The fungal decay occurring commonly throughout postharvest storage causes high loss of value on the market (Hernández-Muñoz et al., 2008).

Most studies were conducted to extend the postharvest life of strawberry planted in soil, however, report about hydroponic strawberry is still limited. Recently, cultivation of strawberry using hydroponic method becomes popular in Vietnam. In this context, we carried out the experiment to evaluate the effect of edible coating chitosan or chitosan-calcium gluconate on postharvest life of hydroponic strawberry stored at $10{ }^{\circ} \mathrm{C}$ for 10 days.

\section{MATERIALS AND METHODS}

\section{Material}

Hydroponic strawberries (Fragaria vesca L.) were harvested from a Big Bear orchard in Lam Dong Province, Vietnam. Fruit was transported to the laboratory (Ho Chi Minh City, Vietnam) in a refrigerated van and treatments were applied within $24 \mathrm{~h}$ of harvest. Fruit temperature is 10 $\pm 1.0{ }^{\circ} \mathrm{C}$ before treatment and during cold storage.

Chitosan (molecular weight of about $120 \mathrm{kDa}$ and $80 \%$ deacetylation degree) was provided by Nha Trang University (Nha Trang City, Vietnam). Calcium gluconate was provided by Vadhani Ind Estate (Mumbai, India). 


\section{Coating formulation}

Acetic acid solution of $1 \%$ was prepared.

Chitosan solution was prepared by dissolving $1 \%$ or $1.5 \%$ chitosan in $1 \%$ acetic acid solution.

The preparation of coating formulation containing $1.5 \%$ chitosan and $0.5 \%$ calcium gluconate was followed Hernández-Muñoz et al. (2008). Firstly, calcium salt at $0.5 \%$ was dissolved in water prior to the incorporation of the acetic acid, and then chitosan was added.

\section{Sample treatments}

Strawberry was selected for experiments based on size, shape, red surface color (2/3 of fruit) and freedom from external damage and fungal infection. Samples were randomly divided into 4 groups including 3 treated groups and one control.

Three groups were immersed for $30 \mathrm{~s}$ in $1 \%$ CS, $1.5 \%$ CS or $1.5 \%$ CS-CaGlu, respectively. After treatment, fruit was dried at room temperature for $2 \mathrm{~h}$. All samples were packed in plastic bags with 8 holes of $6 \mathrm{~mm}$ diameter. There were 30 bags per group and 10 berries per bag. All groups were stored at cold temperature $\left(10 \pm 1{ }^{\circ} \mathrm{C}, \mathrm{RH} 90 \%\right)$. Uncoated sample served as control.

\section{Measurements}

Measurements were carried out on day 0 (just after coating and air drying) and each day during storage period. Three packages from each group were removed from chamber each day for analysis of weight loss, firmness, total soluble solid, $\mathrm{pH}$, external color, and visual quality during storage period.

Weight loss. The difference between initial (day 0) and each interval was considered as total weight loss during that interval and calculated as percentages of the fresh weight (HernándezMuñoz et al., 2008).

Surface color. External color of strawberry was measured with a portable Minolta Chroma Meter CR-400 (Minolta Corporation, Osaka, Japan). Standard CIE $L^{*}, a^{*}, b^{*}$ color characteristics were determined at 3 points on each fruit surface. The hue angle and chroma were calculated based on $b^{*}$ and $a^{*}$ values (Hernández-Muñoz et al., 2008).

Firmness. Firmness of hydroponic strawberry was measured using a penetrometer (Fruit Texture Analyzer, TR Turoni - Italy) with a probe (cylindrical flat bottom and the diameter of 5 $\mathrm{mm}$ ). The firmness was defined as the maximum force used to penetrate to a depth of $7 \mathrm{~mm}$ in the fruit shoulder zone. Data were collected from 30 strawberries and expressed in newton (N) (Yan et al., 2019).

Total soluble solid content. Soluble solid content of strawberry (TSC, \%) was determined by a hand-held refractometer (Yieryi THE01505, Guangdong, China) using freshly squeezed liquid according to Hitka et al. (2014).

\section{$\mathrm{pH}$}

Six grams of strawberry were homogenized, suspended in $100 \mathrm{~mL}$ of distilled water and then filtered. After that, the $\mathrm{pH}$ of filtrate was measured by a hand-held $\mathrm{pH}$ meter (Testo 206-pH1) according to Hernández-Muñoz et al. (2008). 


\section{Fungal decay}

Decay was evaluated by visual evaluation as fungal mycelia appeared on fruit surface and calculated as the number of decayed samples divided by initial number of samples multiplied by 100 (Hernández-Muñoz et al., 2008).

\section{Statistical analysis}

All data were processed by R version 4.0.1 (The R Foundation for Statistical Computing, Vienna, Austria) and RStudio version 1.3.959 (RStudio, Boston, US) using Pearson correlation analysis and analysis of variance (ANOVA) followed by TukeyHSD method with significance level of $P<$ 0.05. Effect of factors (coating and storage time) was compared using ANOVA F values. The results on figures were reported as mean with standard deviation.

\section{RESULTS AND DISCUSSION}

\section{Fungal decay}

Strawberry is mainly consumed as fresh produce, however, it has a short postharvest life due to high softening rate and susceptibility to microbial decay (Yan et al., 2019). The quality of berry decreases rapidly and loses the marketability after harvest within few days. In this work, coating preserved strawberry quality compared to the control. Fig. 1 showed the decay percentage of different groups during storage.

Microbial development occurred on control group at the 5th day of the storage period whereas the early signs of decay appeared at the 8th day in $1 \%$ chitosan treated fruit. No visible sign of decay was detected for samples coated with $1.5 \%$ CS or CS-CaGlu during the storage. Coating obtained the positive results in delaying microbial growth. At the end of experiment,

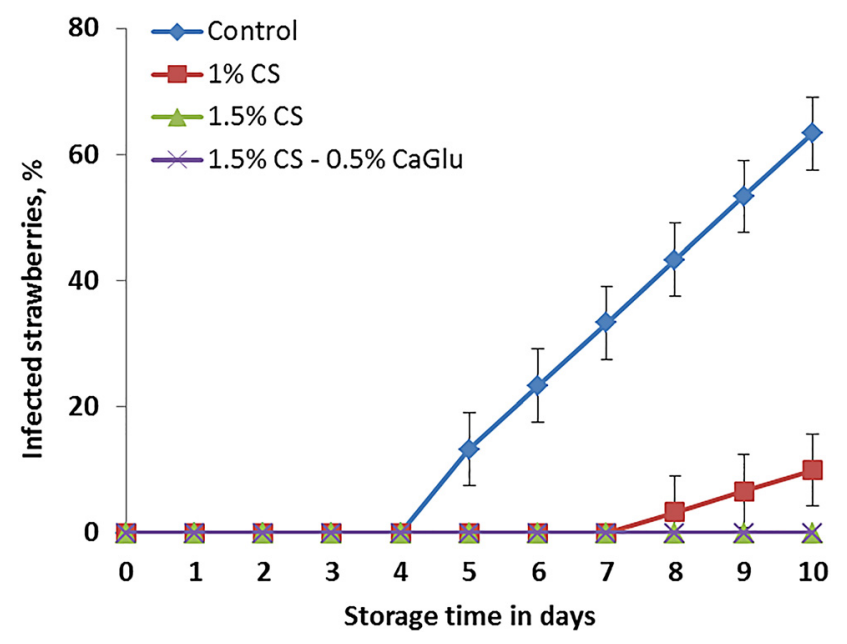

Fig. 1. Decay percentage of strawberry during storage 
control fruit had above $60 \%$ of decay, whereas, fruit treated with $1 \%$ CS was around $10 \%$. There was no difference among group treated with $1.5 \%$ CS and CS-CaGlu. Our results showed that the CS treatment declined the decay of strawberry during 10 days of storage, coincided with the previous report (Hernández-Muñoz et al., 2008).

\section{Weight loss}

Weight loss of all samples occurred as the storage time increased (Fig. 2). The weight loss of control sample rose significantly during storage, whereas weight loss of treated fruit increased gradually. At the end of experiment, weight loss was around $10 \%$ for control sample, and $5 \%$ for fruit treated with $1 \%$ CS.

The weight loss of control was much higher during the experiment compared to treated groups. The greatest change of strawberry quality over storage was in weight loss. The weight loss of berry was influenced by coating. There was a significant difference in weight loss between coated sample and control $(P<0.001)$. Generally, weight loss of sample treated with $1.5 \%$ CS was lower than the maximum acceptance of approximately $3 \%$ for berry (Nunes \& Emond, 2007), whereas the weight loss of control and 1\% CS treated sample was higher than the acceptance limit. This indicated that coating and concentration of CS solution played an important role in minimizing the weight loss of berry. Hydroponic strawberry has a thin skin, making it susceptible to rapid water loss. CS coating acts as barriers to moisture loss, so restricting water transfer, sealing small surface-wounds, thus the dehydration could be delayed (Bautista-Baños et al., 2006). Our results are in agreement with similar finding (Zsivanovits et al., 2018).

\section{Total soluble solid and $\mathrm{pH}$}

Total soluble solid and $\mathrm{pH}$ of strawberry increased gradually over cold storage period for all samples (Fig. 3).

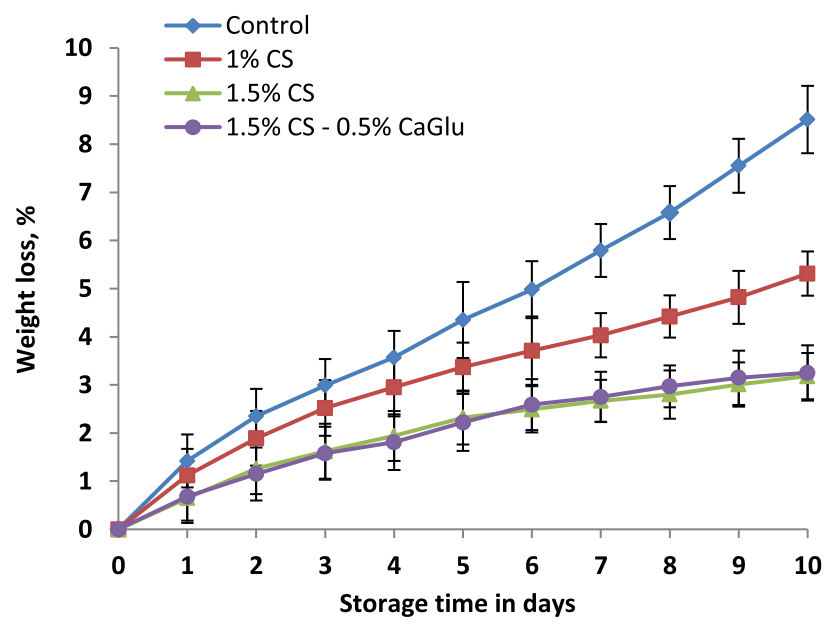

Fig. 2. Weight loss of strawberry during storage 

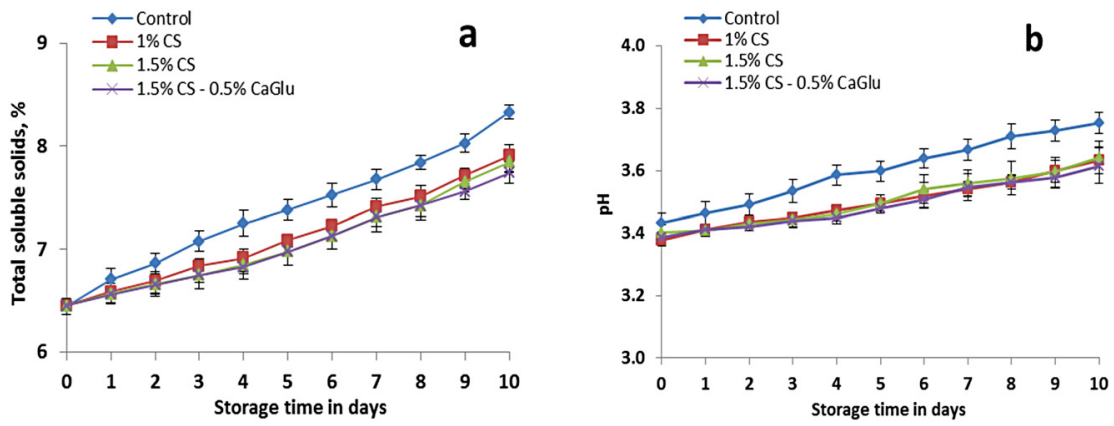

Fig. 3. Total soluble solid (a) and $\mathrm{pH}(\mathrm{b})$ of strawberry during storage

No significant difference in total soluble solid and $\mathrm{pH}$ was observed between coated groups during cold storage. Coating affected total soluble solid and $\mathrm{pH}$ along with storage period compared to the control samples. The total soluble solid and $\mathrm{pH}$ of control fruit had higher values than that of treated sample. The changes in $\mathrm{pH}$ were approximately 0.2 for coated samples and 0.3 for control fruit. The increase in $\mathrm{pH}$ during storage could be due to the loss of water and the control sample suffered the greater loss in water than the coated fruit. In addition, the differences found in total soluble solid and $\mathrm{pH}$ could also relate to the stage of ripeness.

\section{Fruit firmness}

Fig. 4 presented the changes in firmness of strawberry during storage period.

The firmness of coated samples decreased slightly throughout 10 days of cold storage at 10 ${ }^{\circ} \mathrm{C}$, whereas firmness of control fruit declined more strongly, particularly at the end of experiment. The decline in firmness might be due to the ripening of commodity. At the end of measurement, the control fruit had the lowest value in firmness due to advanced ripening compared to other groups.

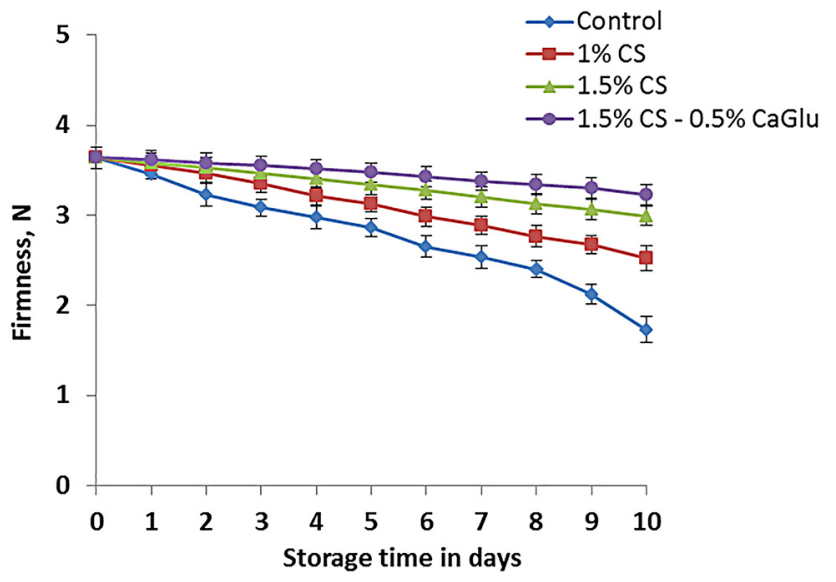

Fig. 4. Firmness of strawberry during storage 
Control sample was softer than coated samples at the end of experiment. It was in agreement with previous study for strawberry (Hernández-Muñoz et al., 2008). Those authors found that control and fruit treated with CS alone had lower values in firmness than fruit coated with CSCaGlu. The combination of CS and CaGlu had benefit in retaining the firmness of fruit because calcium maintains the cell wall structure in fruit (Hernández-Muñoz et al., 2008). Calcium interacts with the pectic acid in the cell walls to form cross-links between pairs of negatively charged homogalacturonans, thus enhances the tightening of the cell wall. The effect of external calcium is partially related to strengthening the cell wall structure due to incorporation of $\mathrm{Ca}^{2+}$ into the middle lamella (Lara et al., 2004).

\section{Surface color}

The changes in surface color were showed in Fig. 5. The lightness, hue angle and chroma declined during storage.

The $L^{*}$ parameter showed the changes in fruit darkening. Fig. 5a showed that $L^{*}$ value declined as increasing storage time for all samples, however, the control became more darker than other groups. The color change to red is often the sign of ripening. The hue angle value had a strong shift to red during storage in case of control and gradual change in case of coated fruits (Fig. 5b). The decline in chroma showed that samples had less vivid coloration during storage (Fig. 5c). CS coating could delay the ripening of strawberry. The combination of CS and CaGlu did not show any additional effect on postponing fruit ripening. It was in agreement with previous report (Barikloo and Ahmadi, 2018).
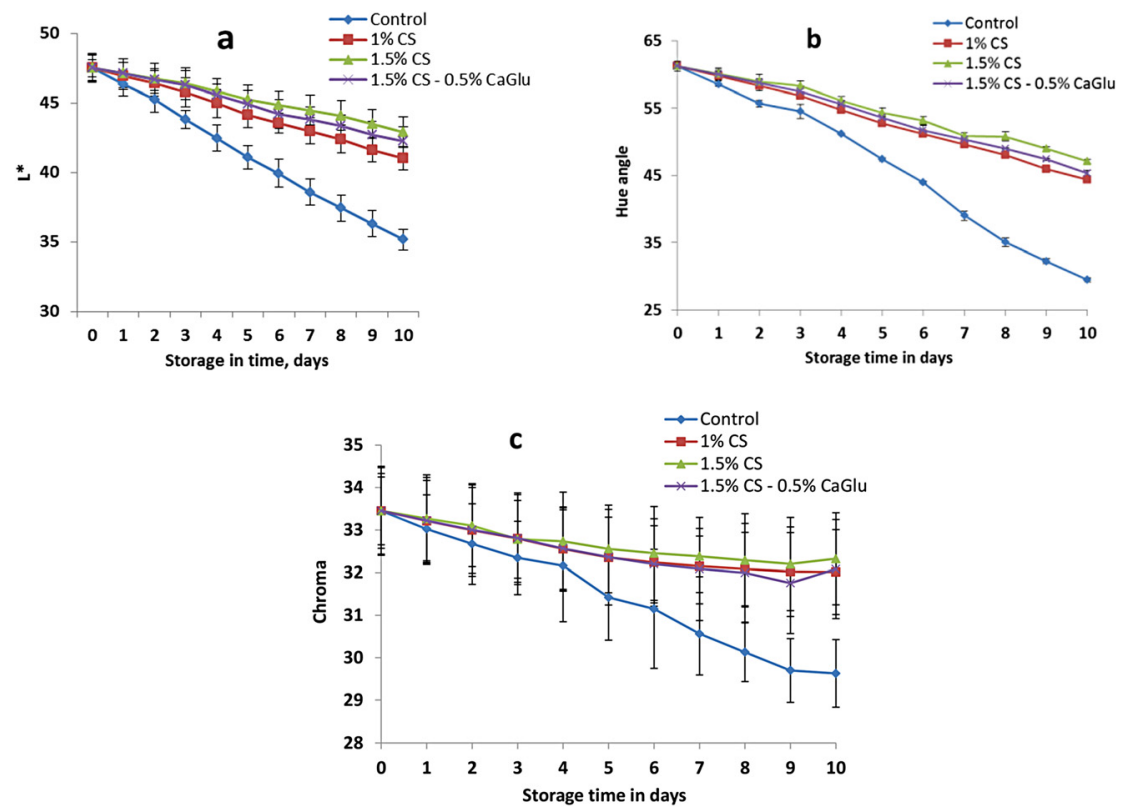

Fig. 5. Surface color evolution: lightness (a), hue angle (b) and chroma (c) of strawberry during storage 
Table 1. Pearson correlation on all values $(N=132)$

\begin{tabular}{lcccrrr}
\hline & Hue & Chroma & Weight loss & Firmness & $\mathrm{pH}$ & \multicolumn{1}{c}{ SSC } \\
\hline CIE L $^{*}$ & $-0.945^{+}$ & $0.391^{+}$ & $-0.856^{+}$ & $0.945^{+}$ & $-0.879^{+}$ & $-0.856^{+}$ \\
Hue & & 0.167 & $-0.925^{+}$ & $0.902^{+}$ & $-0.933^{+}$ & $-0.931^{+}$ \\
Chroma & & & -0.010 & $0.277^{+}$ & -0.206 & -0.250 \\
Weight loss & & & & $-0.881^{+}$ & $0.854^{+}$ & $0.837^{+}$ \\
Firmness & & & & $-0.843^{+}$ & $-0.840^{+}$ \\
pH & & & & & & $0.916^{+}$ \\
\hline
\end{tabular}

$+P<0.001$.

\section{Correlation}

Significant correlation $(N=132, P<0.001)$ was observed among color and physico-chemical parameters (Table 1). The color parameter chroma obtained the lowest correlation values with physico-chemical parameters $(r \leq 0.277)$. The brightness of fruit surface (CIE L*) reached its highest correlation of $r=0.945$ with firmness. The hue angle reached its highest correlation of $r=0.933$ with $\mathrm{pH}$ and obtained similar high correlation with SSC $(r=0.931)$ and weight loss $(r=0.925)$. The strong relationship between appearance and reference attributes supports consumers' choice, since they search for attractive fruit on the market. The relationship between appearance and measured physico-chemical parameters is stronger than that of physico-chemical parameters. The correlation between $\mathrm{pH}$ and SSC was $r=0.916$, while other values including weight loss, firmness, $\mathrm{pH}$, and SSC were all significant with $r \geq 0.837$. The significant correlation values and strong relationship between these reference attributes also show the postharvest changes of fruit during storage. These observations are in agreement with literature.

Analysis of Variances (ANOVA) test was performed to evaluate the effect of storage time, applied coating on measured values. Besides the main effects, interaction effect of storage time and coating was also computed (Table 2). While $\mathrm{F}$ values of main effects show the contribution of single factor of storage time or coating, significant $F$ values of interaction effect show different kinetics of samples of different coating. The most sensitive parameter was the hue angle with its highest significant $F$ values $(P<0.001)$. The less sensitive response was observed for chroma, probably due to its high natural variability.

Table 2. Analysis of variance $F$ values

\begin{tabular}{lccc}
\hline Parameter & Storage time & Coating & Storage time $\times$ Coating \\
\hline CIE L* & $78.97^{++}$ & $126.49^{++}$ & $4.89^{++}$ \\
Hue & $1788.05^{++}$ & $1615.43^{++}$ & $87.37^{++}$ \\
Chroma & $3.07^{+}$ & 0.2 & 0.92 \\
Weight loss & $93.62^{++}$ & $129.2^{++}$ & $8.85^{++}$ \\
Firmness & $99.77^{++}$ & $226.43^{++}$ & $9.03^{++}$ \\
pH & $86.87^{++}$ & $83.98^{++}$ & $0.98^{++}$ \\
SSC & $193.84^{++}$ & $56.16^{++}$ & $1.17^{++}$ \\
\hline
\end{tabular}

${ }^{++} P<0.001 ;{ }^{+} P<0.01$. 


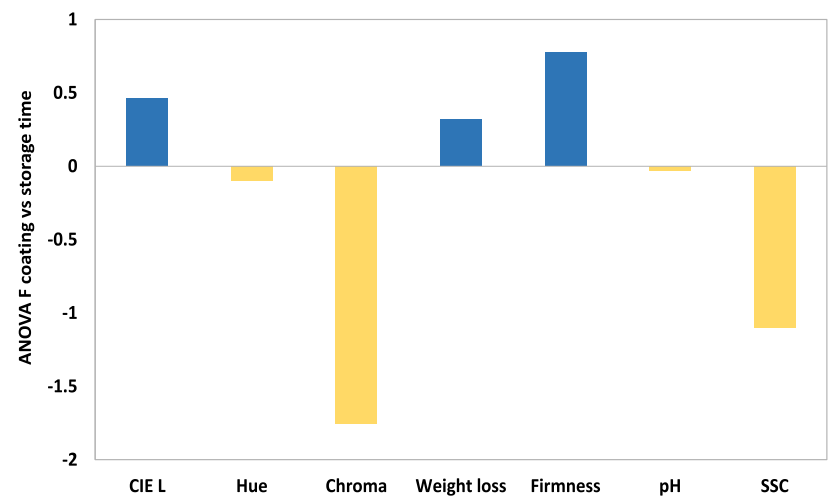

Fig. 6. Statistical power of coating and storage time on measured parameters

\section{Analysis of variance $F$ values}

Statistical power of coating was calculated based on the ANOVA $F$ value (response of parameter) according to the following equation:

$$
E=\frac{F_{\text {coating }}-F_{\text {time }}}{\frac{1}{2}\left(F_{\text {coating }}+F_{\text {time }}\right)}
$$

In the above equation (Eq. (1)), the difference of $\mathrm{F}$ values is normalized with their average. As a result, positive values indicate the stronger sensitivity of parameter to coating, while negative values indicate stronger response to storage time. Calculated statistical power is presented in Fig. 6. Chroma was reduced throughout storage for all samples, however, differences in chroma between coated and control samples only became significant at the end of storage period. The changes of chroma in strawberry were greatly influenced by storage time. There was no difference among variously coated samples. Also, for total soluble solid content, no significant difference was found between coated fruit over the storage period. The total soluble solid content increased with storage time for all samples. The differences found in total soluble solid of strawberries could be due to natural variability of ripening stage.

According to the statistical power, application of coating can significantly slow down postharvest changes in CIE L*, weight loss, and firmness.

\section{CONCLUSION}

The study presented the effect of edible coating on postharvest life of hydroponic strawberry. The result of this work indicated that coating hydroponic strawberry with CS or CS-CaGlu could reduce weight loss, softening, and surface color change during storage. In addition, postharvest decay of coated fruit also decreased, compared to the control. The concentration of CS solution also affected the strawberry quality over the storage period. The combination of CS and CaGlu has potential in maintaining the quality of commodity throughout storage. 


\section{ACKNOWLEDGEMENTS}

The Project is supported by the European Union and co-financed by the European Social Fund (Grant Agreement No. EFOP-3.6.3-VEKOP-16-2017-00005). This research was supported by the Ministry for Innovation and Technology within the framework of the Higher Education Institutional Excellence Program (NKFIH-1159-6/2019) in the scope of plant breeding and plant protection researches of Szent István University.

\section{REFERENCES}

Adiletta, G., Zampella, L., Coletta, C., and Petriccione, M. (2019). Chitosan coating to preserve the qualitative traits and improve antioxidant system in fresh figs (Ficus carica L.). Agriculture, 9(4): 84.

Baranyai, L., Nguyen, L. L. P., Sao Dam, M., Zsom, T., and Hitka, G. (2020a). Evaluation of precooling temperature and 1-MCP treatment on quality of 'Golden Delicious' apple. Journal of Applied Botany and Food Quality, 93: 130-135.

Barikloo, H. and Ahmadi, E. (2018). Shelf life extension of strawberry by temperatures conditioning, chitosan coating, modified atmosphere, and clay and silica nanocomposite packaging. Scientia Horticulturae, 40: 496-508.

Bautista-Baños, S., Hernandez-Lauzardo, A.N., Velazquez-Del Valle, M.G., Hernández-López, M., Barka, E.A., Bosquez-Molina, E., and Wilson, C. (2006). Chitosan as a potential natural compound to control pre and postharvest diseases of horticultural commodities. Crop protection, 25(2): 108-118.

Dalmadi, I., Kántor, D., Wolz, K., Polyák-Fehér, K., Pásztor-Huszár, K., Farkas, J., and Fekete, A. (2007). Instrumental analysis of strawberry puree processed by high hydrostatic pressure or thermal treatment. Progress in Agricultural Engineering Sciences, 3(1):47.

Duan, C., Meng, X., Meng, J., Khan, M. I. H., Dai, L., Khan, A., An, X., Zhang, J., Huq, T., and Ni, Y. (2019). Chitosan as a preservative for fruits and vegetables: a review on chemistry and antimicrobial properties. Journal of Bioresources and Bioproducts, 4(1): 11-21.

Jesus Filho, M.d., Scolforo, C.Z., Saraiva, S.H., Pinheiro, C.J.G., Silva, P.I., and Della Lucia, S.M. (2018). Physicochemical, microbiological and sensory acceptance alterations of strawberries caused by gamma radiation and storage time. Scientia Horticulturae, 238: 187-194.

Hazarika, T.K., Lalrinfeli, L., Lalchhnmawia, J., and Mandal, D. (2019). Alteration of quality attributes and shelf-life in strawberry (Fragaria $\mathrm{x}$ ananssa) fruits during storage as influence by edible coating. Indian Journal of Agricultural Sciences, 89(1): 28-34.

Hernández-Muñoz, P., Almenar, E., Valle, V. D., Velez, D., and Gavara, R. (2008). Effect of chitosan coating combined with postharvest calcium treatment on strawberry (Fragaria $\times$ ananassa) quality during refrigerated storage. Food Chemistry, 110(2): 428-435.

Hitka, G., Zsom, T., Nguyen, L.P.L., and Balla, Cs. (2014). Effect of 1-methylcyclopropene on 'Bosc Kobak'pears. Acta Alimentaria, 43(Supplement 1): 73-77.

Lara, I., García, P., and Vendrell, M. (2004). Modifications in cell wall composition after cold storage of calcium-treated strawberry (Fragaria $\times$ ananassa Duch.) fruit. Postharvest Biology and Technology, 34(3): 331-339.

Nguyen, L.P.L., Szabó, G., Hitka, G., Zsom, T., Tóth, A., Németh, C., and Kókai, Z. (2018). Effect of ethylene absorber on banana during storage. Acta Horticulturae, 1216: 55-58. 
Nguyen, L. P. L., Zsom, T., Sao Dam, M., Baranyai, L., and Hitka, G. (2020a). Comparison of 1-MCP treatment on four melon cultivars using different temperatures. Journal of Applied Botany and Food Quality, 93: 122-129.

Nguyen, L.P.L., Visy, A., Baranyai, L., Friedrich, L., and Mahajan, P.V. (2020b). Application of hue spectra fingerprinting during cold storage and shelf-life of packaged sweet cherry. Journal of Food Measurement and Characterization, 14: 2689-2702.

Nunes, C.N. and Emond, J.P. (2007). Relationship between weight loss and visual quality of fruits and vegetables. Proceedings of the Florida State Horticultural Society, 120: 235-245.

Rux, G., Mahajan, P.V., Linke, M, Pant, A., Sängerlaub, S., Caleb, O.J., Geyer, M., and Sven. (2016). Humidity-regulating trays: moisture absorption kinetics and applications for fresh produce packaging. Food and Bioprocess Technology. 9(4): 709-716.

Yan, J., Luo, Z., Ban, Z., Lu, H., Li, D., Yang, D., Aghdam, M.S., and Li, L. (2019). The effect of the layer-bylayer (LBL) edible coating on strawberry quality and metabolites during storage. Postharvest Biology and Technology, 147: 29-38.

Zsivanovits, G., Grancharova, T., Dimitrova-Dyulgerova, I., Ivanova, D., Kostadinova, S., and Marudova, M. (2018). Postharvest quality and safety of fresh-cut melon fruits coated with water soluble chitosan films. Progress in Agricultural Engineering Sciences, 14(s1): 133.

Open Access. This is an open-access article distributed under the terms of the Creative Commons Attribution 4.0 International License (https://creativecommons.org/licenses/by/4.0/), which permits unrestricted use, distribution, and reproduction in any medium, provided the original author and source are credited, a link to the CC License is provided, and changes - if any - are indicated. (SID_1) 